\title{
WALMART: UM PROJETO PARA A BASE DA PIRÂMIDE NO BRASIL ${ }^{1}$
}

\section{Ana Paula Miotto}

Escola de Administração de Empresas de São Paulo, Fundação Getulio Vargas

\section{Edgard Barki}

Escola de Administração de Empresas de São Paulo, Fundação Getulio Vargas

\section{Introdução}

Em meados de 2010, o Diretor do Instituto Walmart Brasil, Paulo Mindlin, estava reunido com uma de suas gerentes, Adriana Franco, para discutirem os rumos do programa de desenvolvimento local na comunidade da Bomba do Hemetério, na cidade de Recife, que completava dois anos.

Mais do que um balanço do que aconteceu nos dois primeiros anos, os executivos precisavam rever os planos para os próximos anos do programa e decidir se o Instituto continuaria com investimentos sociais desse tipo em outras comunidades. "A principal pergunta a ser respondida é o que aprendemos até agora e como podemos aproveitar essa expertise em outros programas", provoca Mindlin.

Em um país com tantas demandas sociais, a replicabilidade de programas sociais é fundamental para a ampliação do escopo das iniciativas que visam ao desenvolvimento social.

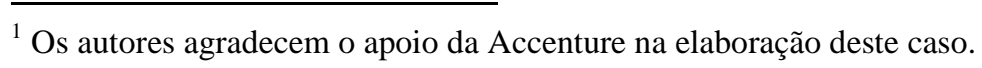

\section{CFGV-EAESP/RAE 2010}

Todos os direitos reservados. Permitida a citação parcial, desde que identificada a fonte. Proibida a reprodução total. Em caso de dúvidas, consulte a Redação: gvcasos.redacao@fgv.br; (11) 3799-3717 
Outra questão ainda precisa ser respondida: "como construir uma conexão com o negócio da empresa, como criar sinergia entre esse tipo de ação social e o nosso negócio?”, complementa Franco. Mindlin e Franco sabiam que as respostas a essas perguntas eram fundamentais para o futuro do Instituto Walmart, que tinha como objetivo incorporar de maneira mais efetiva as ações de responsabilidade social às estratégias da empresa. Naquele momento, era importante criar sinergia entre o negócio da empresa e as práticas de responsabilidade social, para criar uma relação de ganha-ganha mais nítida.

\section{Walmart no Brasil}

Segundo a lista das 500 maiores empresas americanas da revista Fortune, o Walmart aparecia em primeiro lugar do ranking de 2010, com faturamento de mais de US\$ 408 bilhões, contando mais de 7.900 lojas em 15 países.

A maior empresa varejista do mundo chegou ao Brasil em 1995, encontrando um ambiente competitivo, com grandes empresas já estabelecidas. Quinze anos após sua chegada, a rede contava com lojas em 18 estados, além de no Distrito Federal, nas regiões Nordeste, Centro-Oeste, Sudeste e Sul. Após um começo difícil e com crescimento orgânico, o Walmart iniciou um processo de forte expansão por meio da aquisição de grandes redes varejistas, como o Bompreço, no Nordeste, e o Sonae, na região Sul. A empresa optou, em suas aquisições, por manter as marcas originais em suas lojas, trabalhando com uma estratégia multibandeira e multiformato, possuindo hipermercados, supermercados, cash \& carry, clube de compras e atacado (veja todos os formatos e bandeiras do Walmart Brasil no anexo 1).

No final de 2009, a rede possuía 435 lojas e 80 mil funcionários. Com faturamento de $\mathrm{R} \$ 19,7$ bilhões em 2009, ocupava a terceira posição no ranking da Associação Brasileira de Supermercados (Abras), atrás do Grupo Pão de Açúcar, com faturamento de R \$ 26,2 bilhões, e do Carrefour, com R\$ 25,6 bilhões. 
Depois de um processo de crescimento acelerado baseado em aquisições, o Walmart, desde 2009, investiu fortemente na abertura de novas lojas, em uma estratégia de crescimento orgânico. A previsão é de um investimento de $\mathrm{R} \$ 2$ bilhões a $\mathrm{R} \$ 2,2$ bilhões em 2010 para a abertura de entre $100 \mathrm{e}$ 110 lojas, em diversos formatos, com ênfase nas bandeiras Todo Dia (varejo) e Maxxi (cash \& carry), que atendem principalmente os públicos da base da pirâmide (veja, no anexo, 2 a missão, a visão e os valores do Walmart Brasil).

\section{Walmart e sustentabilidade}

Mundialmente, o Walmart tem investido muitos recursos em sustentabilidade. Desde a tragédia causada pelo furacão Katrina, em 2005, em que o Walmart, em conjunto com outras empresas com grande poder logístico, conseguiu suprir a população de New Orleans com comida e água, o tema de sustentabilidade passou a fazer parte central do modelo de negócios da empresa.

Em outubro de 2005, o presidente e CEO do Walmart, Lee Scott, fez um pronunciamento em Bentonville, transmitido para 1,6 milhão de empregados e mais de 60 mil fornecedores, nas mais de seis mil lojas da empresa, para divulgação da sua estratégia de sustentabilidade. O objetivo principal dessa estratégia era reduzir o impacto das suas operações no meio ambiente e, assim, tornar a companhia a mais competitiva e inovadora no mundo. Nessa ocasião, foram lançadas três grandes metas: utilizar $100 \%$ de energia renovável, criar resíduo zero e vender produtos que estejam comprometidos com a sustentabilidade.

Essas iniciativas estão restritas ao aspecto ambiental da sustentabilidade, em detrimento dos aspectos sociais e de sustentabilidade econômica. Essa estratégia tem como objetivo principal ser mais amigável ao ambiente.

\section{Instituto Walmart Brasil}

Consciente do maior foco dado às questões ambientais da sustentabilidade, a empresa resolveu dar uma resposta às demandas sociais fundando, em novembro de 2005, o Instituto Walmart no Brasil, 
com o objetivo de dar mais atenção aos aspectos relacionados à responsabilidade social. Uma preocupação comum aos executivos do Walmart norteou a criação do Instituto: "não queríamos ser um instituto que atira para todo lado. Em um país com tantas demandas sociais, esse é um risco, e definir quais são as causas mais importantes para apoiar não é uma tarefa fácil”, relembra Paulo Mindlin (veja, no anexo 3, a missão e a visão do Instituto).

Inicialmente, o foco do Instituto eram ações sociais e culturais, e a estratégia era desenvolver programas pontuais com o objetivo de aprender com eles para, posteriormente, buscar concentrar os esforços em causas definidas, buscando a transformação das comunidades onde fosse realizado o investimento social privado.

O Instituto Walmart, hoje, possui três causas:

- Desenvolvimento Local - Bomba do Hemetério em Recife e Flona do Amapá, na Amazônia;

- Escola Social do Varejo - atua na formação de jovens para o varejo, uma iniciativa de usar o conhecimento intrínseco da empresa;

- Economia Inclusiva - incentivo à formação, capacitação, acesso a crédito e mercado para microempreendedores e cooperativas.

\section{Programa de desenvolvimento local da Bomba do Hemetério}

Após a definição pela implementação de um programa de desenvolvimento local, a equipe do Instituto Walmart iniciou a busca por uma comunidade que pudesse receber esse tipo de investimento social. No entanto, uma decisão anterior precisava ser tomada: em qual cidade brasileira seria iniciada a busca.

Uma combinação de fatores acabou levando à escolha de Recife como a primeira cidade a participar do primeiro programa de desenvolvimento local do Instituto. Em 2007, o então presidente do Walmart Brasil, Vicente Trius, visitou Recife, sede da regional do Walmart no Nordeste e que, 
anteriormente, servia de sede da rede Bompreço, adquirida pela empresa em março de 2004, e ficou sensibilizado com as demandas sociais visíveis.

A importância da operação de Recife para o Bompreço, aliada à importância do Nordeste como um todo para o negócio do Walmart e às necessidades de investimento social em Recife, colaborou para a escolha da cidade para o programa.

A escolha da comunidade foi um processo que durou cerca de oito meses e envolveu uma série de estudos com dados secundários ${ }^{2}$ e visitas a diversos bairros. Após a seleção de três comunidades, a validação da escolhida foi feita por um comitê formado por executivos do Walmart e membros do Instituto.

O objetivo principal do programa era "promover o desenvolvimento local integrado e sustentável da comunidade por meio de ações que contribuam para o aumento da renda, melhoria da qualidade dos serviços básicos, fortalecimento das manifestações culturais locais, mobilização e organização comunitária”.

Segundo Karina Zapatta, do Instituto de Assessoria para Desenvolvimento Humano (IADH), o desenvolvimento local "se alicerça em três eixos: o capital social organizado, ou seja, as pessoas organizadas, conscientes e protagonistas dos processos; o desenvolvimento socioprodutivo, que se traduz na comunidade organizada com bons programas que gerem renda e inclusão social, e, o maior desafio, a nova governança, que nada mais é do que a união do setor privado, do setor público e da sociedade civil organizada para os processos decisórios de desenvolvimento do bairro".

O programa foi desenhado visando à integração de vários parceiros técnicos, especialistas em diferentes áreas do investimento social, que auxiliariam o Instituto Walmart a desenvolver os subprojetos em cada uma das áreas de atuação: gestão do desenvolvimento e mobilização social, capacitação, geração de trabalho e renda e produção de conhecimento.

\footnotetext{
${ }^{2}$ Veja o atlas de desenvolvimento humano em Recife em: http://www.recife.pe.gov.br/pr/secplanejamento/pnud2006/.
} 
Inicialmente, o programa foi definido para ter duração de cinco anos, dessa forma esperava-se que, nesse intervalo de tempo, a comunidade fosse capaz de se capacitar e estar pronta para dar andamento aos projetos sem a necessidade da tutela e dos investimentos do Instituto (veja, no anexo 4, a proposta de intervenção entre 2008 e 2013).

\section{O bairro Bomba do Hemetério, em Recife}

A cidade de Recife, capital do estado de Pernambuco, está entre as maiores cidades do Nordeste. Com uma população de 1,4 milhão de habitantes ${ }^{3}$, a cidade tem uma posição estratégica na região e tem recebido muitos investimentos públicos e privados nos últimos anos, com o objetivo de fomentar o seu desenvolvimento.

O bairro da Bomba do Hemetério fica localizado na zona norte da cidade de Recife (veja a localização do bairro no anexo 5). Trata-se de uma área periférica onde se encontra uma concentração de população de baixa renda, tanto no bairro como nas comunidades vizinhas.

A população total da Bomba do Hemetério é de cerca de 12 mil pessoas, predominantemente das classes C e D, com 46\% e 37\%, respectivamente (veja a classificação social no Brasil no anexo 6).

Uma população jovem, com 50\% dos moradores com menos de 30 anos (veja mais dados do censo realizado pelo Instituto Walmart no anexo 7).

Já nos primeiros contatos com a comunidade, ficou clara sua vocação para a indústria cultural. A Bomba concentra mais de 60 grupos culturais envolvidos em diversas atividades: agremiações carnavalescas, grupos de teatro, maracatu, a Orquestra Popular da Bomba do Hemetério etc.

Segundo Juarez, que é artista plástico, morador da Bomba e membro do comitê de apoio: "eu nasci, me criei no bairro e continuo morando lá, não pretendo sair de lá, como morador, não. Às vezes, tem o paradoxo da história da comunidade, que é a violência, as dificuldades financeiras, econômicas e de infraestrutura que ainda existem, e, do outro lado, a riqueza cultural e artística, que é uma coisa

\footnotetext{
${ }^{3}$ População segundo o Censo 2000 em: http://www.recife.pe.gov.br/pr/secplanejamento/inforec/.
} 
impressionante, parece uma coisa espiritual, porque não se veem muitos lugares com uma concentração tão grande de arte e cultura em uma comunidade só".

Essa pluralidade cultural e a quantidade de grupos organizados dão à Bomba do Hemetério uma característica singular. Ao mesmo tempo em que traz grande riqueza cultural, acaba dificultando a união da comunidade em torno de causas comuns e problemas que afligem a comunidade como um todo.

A vocação para a indústria cultural também constitui um desafio para o Instituto Walmart, uma vez que a conexão do programa com o negócio da empresa em uma comunidade com essas características não é direta.

\section{Primeiro ano do programa}

O primeiro ano do programa foi dedicado à mobilização da comunidade e à constituição de um comitê formado por moradores do bairro, que dariam suporte ao programa. Esse comitê foi constituído por pessoas que se interessaram pela proposta e se aproximaram do Instituto.

Muitas dúvidas e desconfiança permearam os primeiros contatos do Instituto e seus parceiros com a comunidade. Como lembrou Juarez: "no início, com a chegada do Instituto, a comunidade ficou desconfiada, na verdade, a comunidade é desconfiada, e com razão, pelo histórico que todos conhecem, de políticos, de promessas e tudo mais".

Essa desconfiança foi intensificada pelo receio de o Walmart abrir uma loja na comunidade e tornar-se concorrente do pequeno varejo local. A comunidade mostrou-se resistente à abertura de uma loja, em solidariedade aos donos dos mercadinhos do bairro, que temiam a concorrência, e, no início, tinha uma postura contrária: "a gente não quer loja aqui porque a gente compra dos mercadinhos e os donos são nossos amigos, cresceram com a gente”. 
Era preciso conquistar a confiança daquelas pessoas e mostrar que a ideia do Instituto Walmart não era comercial. A decisão de investimento em uma nova loja exige intensos estudos de viabilidade econômica e territorial, e o Walmart deixou claro para a comunidade e para os parceiros que o programa de desenvolvimento local não existe com o objetivo de instalar futuramente uma loja na comunidade.

Aos poucos, com os resultados das ações aparecendo e com o envolvimento da comunidade, a confiança foi sendo conquistada e o Instituto teve cada vez mais o apoio dos moradores do bairro e das lideranças locais, unindo forças para que os projetos se realizassem cada vez mais rápido.

Nesse sentido, o IADH e a ONG Auçuba - Comunicação e Educação foram parceiros fundamentais nesse momento de aproximação do Instituto com a comunidade. Os primeiros contatos foram feitos com as lideranças locais, líderes de grupos culturais, dirigentes das escolas do bairro etc.

O objetivo inicial foi capacitar os membros do comitê em desenvolvimento local, liderança e empreendedorismo. Visando ao fortalecimento desse núcleo de pessoas engajadas no programa, foram realizados cursos, workshops e atividades em grupo.

Nesse momento, o grupo ainda não possuía um local próprio para suas reuniões, e a maioria das atividades acabava acontecendo em um espaço cedido por uma escola do bairro.

Uma das primeiras atividades do grupo formado foi a criação do nome do programa e o seu logotipo. O nome Bombando Cidadania é uma referência clara ao nome do bairro e ao objetivo do programa de desenvolvimento local.

As metas principais do Ano 1 podem ser resumidas em:

- Mapeamento das condições sociodemográficas da comunidade;

- Adesão da comunidade e de associados do Walmart ao programa;

- Envolvimento do poder público - implementação de programas governamentais no território;

- Definição das potencialidades locais para elaboração do plano de desenvolvimento e do arranjo produtivo local;

- Início da implantação dos projetos de capacitação e geração de renda. 
Os principais resultados obtidos no primeiro ano são apresentados no anexo 8 .

\section{Segundo ano do programa}

No segundo ano do programa, várias ações foram consolidadas, entre elas, o projeto de geração de renda em uma parceria com a ONG Aliança Empreendedora. Dos sete grupos formados, cinco eram voltados para a produção de artesanato, um para a fabricação de sabão a partir de óleo de cozinha reciclado e outro para produção de alimentos.

Esse projeto levou a mais duas importantes parcerias: o Sebrae, parceiro desde o início do programa, entra nesse momento disponibilizando seus cursos sobre empreendedorismo, e o Centro Pernambucano de Design (CPD), trabalhando diretamente na identidade visual dos produtos elaborados pelos grupos.

Em conjunto com o CPD, foi realizado um estudo iconográfico para identificação dos elementos que pudessem representar a produção artesanal e a própria identidade visual da comunidade. A ideia era resgatar a identificação da comunidade como um grupo organizado, resgatando o orgulho dos moradores em fazer parte dela.

A parceria com o Sebrae e o CPD na orientação dos primeiros grupos produtivos do programa resultou na exposição Bombarte, marcando as comemorações do início do terceiro ano do programa (veja as fotos da exposição no anexo 9), e no lançamento de uma feira de artesanato, que agora ocorre mensalmente no bairro.

Em paralelo aos projetos de geração de renda, os grupos culturais presentes na Bomba iniciaram um processo de criação e disseminação da sua cultura e elegeram a Universidart (um dos grupos culturais já existentes na comunidade) como a instituição local empreendedora e responsável pela dinamização da produção cultural, mobilização e gestão de recursos oriundos do investimento social privado. 


\section{Impactos na comunidade}

Um dos principais impactos do Bombando Cidadania é a recuperação do orgulho de seus moradores pelo bairro, além da melhora da autoestima e do desejo de mostrar o lado bom da comunidade. Os moradores mais envolvidos com o programa citam esses elementos como marcantes e fundamentais para o seu desenvolvimento.

A organização e a capacidade de integração dos diversos parceiros são vistas por todos os envolvidos (Instituto, parceiros e comunidade) como os pontos altos do Bombando Cidadania. Falando da contribuição da empresa para a comunidade, Juarez comenta a importância do apoio financeiro e técnico do Instituto: "tem o apoio financeiro do Walmart, que vem dando também um suporte muito bom na propagação da informação e na elaboração dos projetos mensais. Esse suporte técnico nos faltava. Tinha muita vontade de fazer, mas faltava o caminho das pedras, agora temos orientação, estamos trabalhando e acreditando que esse é um grande momento que a comunidade está vivendo e esse desenvolvimento vai acontecer, já está acontecendo".

A recuperação da imagem do bairro, que já foi um dos mais violentos da cidade, é outro ponto positivo: "quando criança, às vezes, quando íamos para outro bairro ou para a praia, por exemplo, a gente dizia que era da Casa Amarela, um bairro perto da Bomba. Minha mãe pedia para a gente falar isso, porque, se a gente dissesse que era da Bomba, o pessoal em volta já ficava desconfiado. Quando eu falava que era da Bomba, eu sentia a desconfiança", confessou Cleone, morador da Bomba e membro do comitê de apoio. Mostrar também a mudança que está acontecendo na comunidade parece ser um objetivo de todos os envolvidos no programa, Instituto, parceiros e comunidade.

A organização do território e a capacitação das lideranças acabam criando um ambiente mais fértil para ações sociais e iniciativas de outras empresas que veem na comunidade uma oportunidade para implementar suas ações. Exemplos desse tipo são a atuação da companhia de energia elétrica de Pernambuco (Celpe), que considerou a distribuição das geladeiras de seu projeto de eficiência energética, realizada na comunidade da Bomba do Hemetério, extremamente facilitada pela presença do comitê de apoio. 
Outra empresa a se aproximar do Programa Bombando Cidadania foi a Nestlé, que já ministrou cursos do seu programa Nestlé Faz Bem Nutrir na comunidade. Esse programa trabalha a educação alimentar visando combater a desnutrição e a obesidade em crianças e adolescentes de todo o país que vivem em condições socioeconômicas desfavoráveis. Esse programa tem como público educadores, merendeiras e famílias, que participam de oficinas e cursos para um melhor entendimento de conceitos de saúde, higiene e aproveitamento máximo dos alimentos, objetivando um maior ganho nutricional com base nos recursos disponíveis. A utilização do espaço de reuniões da comunidade e o apoio do comitê na organização, divulgação e execução dos cursos foram destacados pela empresa como uma ajuda importante para a execução do programa na Bomba ${ }^{4}$.

Os investimentos nas pessoas e na organização da comunidade são extremamente relevantes em programas de desenvolvimento local. Esse tipo de investimento atrai o desenvolvimento, para Karina Zapatta, do IADH: “quando você investe nas pessoas, na organização, os projetos e o desenvolvimento chegam. Não o contrário, você botar o dinheiro... Não é o dinheiro que gera. É o contrário, o desenvolvimento que gera dinheiro, tanto que agora os parceiros (novos) estão chegando".

No primeiro ano do programa, foi investido, pelo Instituto Walmart, mais de R\$ 1 milhão e, no segundo ano, cerca de R\$900 mil. Além desse investimento, outros parceiros também fizeram investimentos indiretos, com destaque para o Sebrae (em forma de cursos e consultoria) e a Nestlé (por meio do seu programa Nestlé Faz Bem Nutrir).

\section{Metas para o terceiro ano}

O terceiro ano do Bombando Cidadania deve ser marcado por uma maior divulgação do programa na comunidade, com o objetivo de atrair mais moradores e aumentar a mobilização na comunidade. Programas como a Agenda 21, construída pela comunidade para planejar o seu

\footnotetext{
${ }^{4}$ Disponível em: http://www.nestle.com.br/portalnestle/responsabilidadesocial/htm/programa nutrir.html.
} 
desenvolvimento sustentável, deverão ter forte apelo junto aos moradores, devido aos grandes problemas relacionados ao descarte de resíduos e à questão ambiental precária do bairro.

Ações de comunicação também devem ser implementadas, com o objetivo de divulgar o programa tanto interna quanto externamente.

A intensificação do programa de geração de renda, que, no terceiro ano, deverá focar jovens empreendedores individuais, deve ajudar também na mobilização de um número maior de moradores.

\section{Desafios futuros}

O maior desafio apontado pelos envolvidos no programa parece ser a mobilização de uma porção maior da comunidade. Até o segundo ano, cerca de 700 pessoas foram envolvidas em alguma atividade, e a meta é aumentar essa participação.

Uma maior aproximação com o poder público também é desejável. Apesar de alguns contatos pontuais desde o lançamento do programa, tanto o Instituto Walmart quanto os parceiros sentem que uma maior participação do poder público poderia alavancar o desenvolvimento da comunidade, principalmente em áreas como infraestrutura, saúde e educação, que demandam investimentos maiores e que dificilemente conseguiriam ser atendidas exclusivamente com o investimento social privado.

Para o Instituto Walmart, além da maior mobilização da comunidade e aproximação do poder público em torno do programa, existe o desafio de buscar uma conexão do programa de desenvolvimento local com o negócio da empresa e de como replicar a experiência vivida na Bomba para programas em outras comunidades.

Existe o entendimento de que o grande aprendizado, que é o de mobilização e integração de parceiros e comunidade, são conhecimentos que poderão ser aplicados em programas futuros, mas como fazer com que programas como esse, de impacto social tão amplo, extremamente importantes para as comunidades mais carentes, possam ter uma conexão mais clara com o negócio da empresa? 
De volta à sala de reunião no Instituto Walmart, Mindlin e Franco discutem o programa da Bomba do Hemetério. Os ganhos do programa são indiscutíveis, mas trouxeram à tona algumas questões:

- Como e onde investir em novos programas?

- Como aproveitar a experiência adquirida com o Bombando Cidadania?

- Quais deveriam ser os principais objetivos do Instituto Walmart?

- E, principalmente, será que o foco deveriam ser programas mais atrelados ao negócio do Walmart? Como isso poderia ser feito? 
Anexo 1

Walamrt: estrutura de formatos e bandeiras no Brasil

\begin{tabular}{|lll|}
\hline Formato & Bandeira & Região de atuação \\
\hline Hipermercado & BIG & Sul \\
& Walmart & Sudeste e Centro-Oeste \\
& Hiper Bompreço & Nordeste \\
\hline Supermercado & Nacional & Sul \\
& Mercadorama & Sul \\
& Bompreço & Nordeste \\
\hline Loja de vizinhança & Todo Dia & \\
\hline Cash \& carry & Maxxi & \\
\hline Clube de compras & SAM'S CLUB & \\
\hline
\end{tabular}

\section{Anexo 2}

\section{Walmart Brasil}

\section{Missão}

Vender por menos para as pessoas viverem melhor.

\section{Visão}

Ser o melhor varejista do Brasil na mente e no coração dos consumidores e funcionários.

\section{Valores}

- respeito ao indivíduo, seja funcionário, cliente, fornecedor ou membro da comunidade em geral, independentemente de etnia, gênero ou opção sexual;

- atendimento ao cliente, superando as expectativas de nossos consumidores;

- busca pela excelência, inovando sempre na seleção e promoção de produtos e serviços. 
Anexo 3

\section{Instituto Walmart}

\section{Missão}

Promover o autodesenvolvimento para as pessoas viverem melhor.

\section{Visão}

Ser uma organização referência em investimento social.

\section{Anexo 4}

Programa Bombando Cidadania

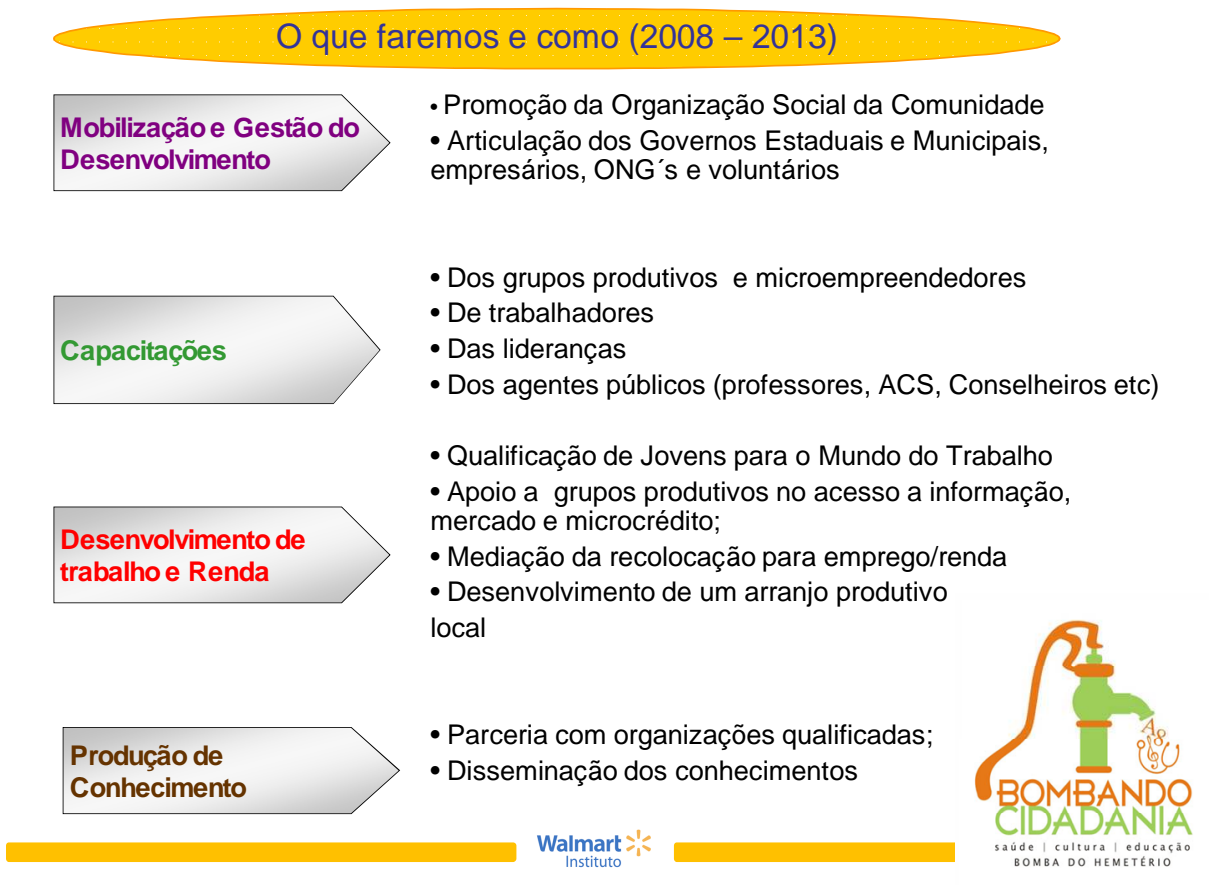




\section{Anexo 5}

Mapa com a localização do bairro Bomba do Hemetério, em Recife

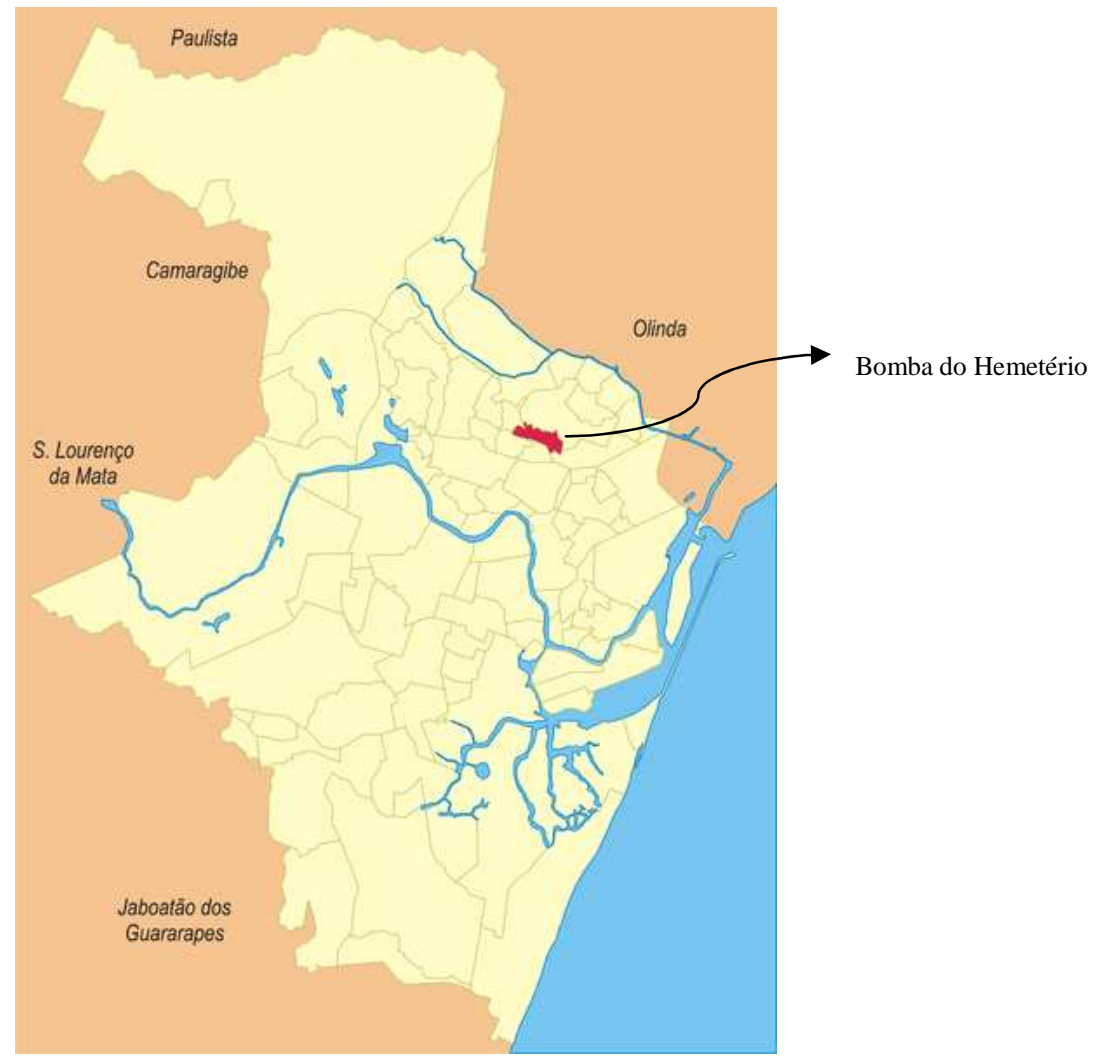


Anexo 6

A- Classificação social no Brasil

\begin{tabular}{|c|c|c|}
\hline $\begin{array}{c}\text { CLASSE } \\
\text { SOCIAL }\end{array}$ & $\begin{array}{c}\text { RENDA FAMILIAR } \\
\text { MENSAL (R\$) }\end{array}$ & $\begin{array}{c}\text { RENDA FAMILIAR } \\
\text { MENSAL (US\$) }\end{array}$ \\
\hline A1 & 14.366 & 8.256 \\
\hline A2 & 8.099 & 4.655 \\
\hline B1 & 4.558 & 2.620 \\
\hline B2 & 2.327 & 1.337 \\
\hline C1 & 1.391 & 799 \\
\hline C2 & 933 & 536 \\
\hline D & 618 & 355 \\
\hline E & 403 & 232 \\
\hline
\end{tabular}

${ }^{1}$ Considerando 1 US\$ = R \$ 1,74, cotação de 1 de janeiro de 2010

Fonte: Associação Brasileira das Empresas de Pesquisa (ABEP)

B- Distribuição das classes sociais no Brasil (2008)

\begin{tabular}{|c|c|c|c|c|c|c|c|c|c|c|}
\hline CLASSE & $\begin{array}{c}\text { Total } \\
\text { Brasil }\end{array}$ & $\begin{array}{c}\text { Gde. } \\
\text { FORT }\end{array}$ & $\begin{array}{c}\text { Gde. } \\
\text { REC }\end{array}$ & $\begin{array}{c}\text { Gde. } \\
\text { SALV }\end{array}$ & $\begin{array}{c}\text { Gde. } \\
\text { BH }\end{array}$ & $\begin{array}{c}\text { Gde. } \\
\text { RJ }\end{array}$ & $\begin{array}{c}\text { Gde. } \\
\text { SP }\end{array}$ & $\begin{array}{c}\text { Gde. } \\
\text { CUR }\end{array}$ & $\begin{array}{c}\text { Gde. } \\
\text { POA }\end{array}$ & DF \\
\hline A1 & $0,6 \%$ & $1,0 \%$ & $0,30 \%$ & $0,5 \%$ & $0,60 \%$ & $0,30 \%$ & $0,6 \%$ & $1,1 \%$ & $0,20 \%$ & $1,5 \%$ \\
\hline A2 & $4,4 \%$ & $3,5 \%$ & $3,3 \%$ & $2,5 \%$ & $3,2 \%$ & $3,5 \%$ & $5,2 \%$ & $5,3 \%$ & $4,9 \%$ & $8,8 \%$ \\
\hline B1 & $9,1 \%$ & $5,2 \%$ & $5,8 \%$ & $6,8 \%$ & $7,7 \%$ & $7,7 \%$ & $10,6 \%$ & $13,4 \%$ & $11,3 \%$ & $13,6 \%$ \\
\hline B2 & $18,0 \%$ & $10,1 \%$ & $10,9 \%$ & $9,4 \%$ & $16,1 \%$ & $17,5 \%$ & $20,6 \%$ & $25,3 \%$ & $22,9 \%$ & $20,4 \%$ \\
\hline C1 & $24,5 \%$ & $14,6 \%$ & $19,7 \%$ & $17,5 \%$ & $24,4 \%$ & $26,7 \%$ & $26,9 \%$ & $23,3 \%$ & $27,1 \%$ & $22,0 \%$ \\
\hline C2 & $23,9 \%$ & $27,9 \%$ & $27,6 \%$ & $31,5 \%$ & $23,8 \%$ & $26,30 \%$ & $21,8 \%$ & $19,4 \%$ & $21,0 \%$ & $17,5 \%$ \\
\hline D & $17,9 \%$ & $30,7 \%$ & $28,1 \%$ & $28,4 \%$ & $23,0 \%$ & $17,0 \%$ & $13,8 \%$ & $10,7 \%$ & $11,9 \%$ & $15,4 \%$ \\
\hline E & $1,6 \%$ & $7,0 \%$ & $4,3 \%$ & $3,4 \%$ & $1,4 \%$ & $0,9 \%$ & $0,6 \%$ & $1,6 \%$ & $0,8 \%$ & $1,0 \%$ \\
\hline
\end{tabular}

Fonte: ABEP 


\section{Anexo 7 \\ Resumo dos resultados do censo da Bomba do Hemetério}

Pesquisa realizada entre os dias 1 e 19 de agosto de 2008, com 3.200 pessoas

Resultados gerais:

- População da Bomba do Hemetério - 12.589 pessoas

- Número total de domicílios no bairro - 3.517

- Percentual de mulheres no bairro - 54\%

- Percentual de habitantes do bairro que têm menos do que 30 anos de idade - $50 \%$

- Percentual dos moradores que são analfabetos $-4 \%$

- Percentual dos moradores que têm apenas o ensino médio - $61 \%$

- Percentual dos domicílios que podem ser classificados como pertencentes

- às classes $\mathrm{C}-46 \%$ e $\mathrm{D}-36 \%$

- Percentual dos domicílios que são beneficiados pelo programa Bolsa Família no bairro - 24\%

- Renda domiciliar mensal média dos moradores da Bomba do Hemetério - R \$ 907,00

- Renda domiciliar per capita do bairro, já contando com os programas de apoio social, como o Bolsa Família - R\$ 300,00 (essa renda representa apenas $40 \%$ da renda domiciliar per capita de Recife)

- IDH da Bomba do Hemetério em 2008, com base nos dados do censo realizado - 0,7632

- Percentual da população da Bomba do Hemetério que está desempregada - 24\% (esse percentual é três vezes maior do que a média de Recife)

\section{Estrutura dos domicílios :}

- Os domicílios são habitados, geralmente, por uma família, havendo, todavia, situações de mais de uma família por casa.

- Os domicílios recebem água da Compesa e possuem algum tipo sistema de esgoto.

- O acesso à internet ainda é bastante limitado e é feito, normalmente, por meio de lan houses.

- Praticamente metade dos domicílios possui crianças em idade escolar, e a grande maioria das crianças encontra-se matriculada em escolas.

Prioridades: segurança, saúde e educação:

- Os resultados indicam, de modo geral, que a segurança, a saúde e a educação são as três áreas que mais preocupam a população da Bomba do Hemetério.

- Embora os entrevistados nem sempre ofereçam respostas diretas sobre suas preocupações, pode-se perceber uma grande preocupação com as questões relacionadas a saúde e segurança.

- Por exemplo, parte significativa dos entrevistados afirma que o bairro é pacífico, mas muitos têm medo de sair à noite e se sentem inseguros em casa. Ou seja, segurança é um problema, mas muitos parecem ter receio de falar diretamente.

- Embora a avaliação dos entrevistados com relação às escolas e aos serviços por elas prestados tenha sido positiva, a educação foi citada como prioridade de investimento no bairro.

- O resultado da educação tem sido similar em várias regiões do país, como demonstrou pesquisa recente publicada pela revista Veja:

- As escolas são fracas, mas nem os pais, nem os filhos, têm parâmetros de comparação para determinar se o que está sendo oferecido poderia ser melhor.

\section{Há demanda e espaço para capacitações:}

- Poucos entrevistados afirmaram ter participado de cursos de capacitação profissional, apesar de a maior parte acreditar que os cursos são importantes.

- Essas informações indicam claramente um espaço de atuação na oferta de cursos que tenham capacidade de elevar as oportunidades de emprego para aqueles que deles venham a participar.

- Os entrevistados indicaram, especificamente, o desejo de fazer cursos de cabeleireiro, informática, enfermagem, corte e costura, eletricista e artesanato. 
- Embora indicados com menor frequência, outros cursos também podem ser de interesse local, desde que ofertados com boa qualidade.

- Exemplos são os cursos de mecânico de automóveis e de bijuterias.

\section{Fraco nível de interação entre pessoas:}

- Os resultados da avaliação da participação em grupos e do nível de confiança entre as pessoas demonstram o baixo grau de interação no bairro.

- Poucas pessoas participam de grupos, e as que o fazem são ligadas a igrejas (católicas ou evangélicas).

- Poucos acreditam que podem contar com os vizinhos para ajudar nas horas difíceis, seja para situações financeiras, para cuidar de crianças ou outras questões.

- Os próprios entrevistados pouco têm participado em atividades que tendem a beneficiar o bairro, e os que se propõem a fazê-lo no futuro dizem que poderão colaborar com tempo, mas não com recursos.

- Há, ainda, indicações de pouca confiança nas autoridades governamentais.

Lazer:

- Os resultados da pesquisa indicam uma carência de estrutura de lazer no bairro.

- As pessoas não têm certeza da existência de equipamentos de lazer no bairro, e mesmo os que sabem da existência de algum equipamento fazem pouco uso deles.

- $\quad$ Em suma, há indicações de espaço para melhorar a infraestrutura e a qualidade dos equipamentos no bairro.

- As agremiações culturais do bairro, por sua vez, são razoavelmente bem conhecidas e bem avaliadas.

- A escola de samba "Gigante do Samba" e a "Orquestra Popular da Bomba do Hemetério" são as mais conhecidas entre a população local e passam uma imagem positiva para a comunidade.

- Por outro lado, o grupo "Tambores do Banzo" é o menos conhecido. Esse grupo está acompanhado de outros, tais como "Boi Teimoso", "José Amâncio do Coco", "Urso Pé de Lã" e os maracatus. 


\section{Anexo 8}

Resultados processuais do programa (2008 a 2010)

\section{- Diagnóstico}

- Pesquisa censitária nos 3.500 domicílios da Bomba do Hemetério;

- Mapeamento da atuação de 60 grupos de arte/cultura;

- Mapeamento das iniciativas empreendedoras produtivas;

- Diagnóstico ambiental participativo.

- Mobilização

- Constituição do comitê local de apoio ao programa com missão, valores e plano de ação definidos;

- Ações voluntárias de associados Walmart.

- Articulação

- Protocolo de intenções firmado com o Governo do Estado e Prefeitura de Recife;

- $\quad$ Adesão de oito parceiros financiadores.

- Implementação dos projetos (oito projetos em execução)

- Comitê local atuando como facilitador da mobilização e gestão do desenvolvimento;

- Agentes comunitários e educadores de creche repassando informações sobre cuidados da primeira infância;

- Kit Bomba do Hemetério utilizado por professores e educadores para uma reflexão com alunos de escolas públicas e programas sociais sobre a realidade da comunidade;

- $\quad$ Nove projetos elaborados pelo coletivo de artistas para estruturação da economia cultural no bairro;

- $\quad$ Nove grupos de microempreendedores com assessoria para o desenvolvimento dos seus planos de negócio;

- Programa de educação profissional de jovens com média de $80 \%$ de inserção no mercado de trabalho;

- Aumento relativo de $30 \%$ na renda dos grupos produtivos acompanhados. 


\section{Anexo 9}

\section{Exposição Bombarte}

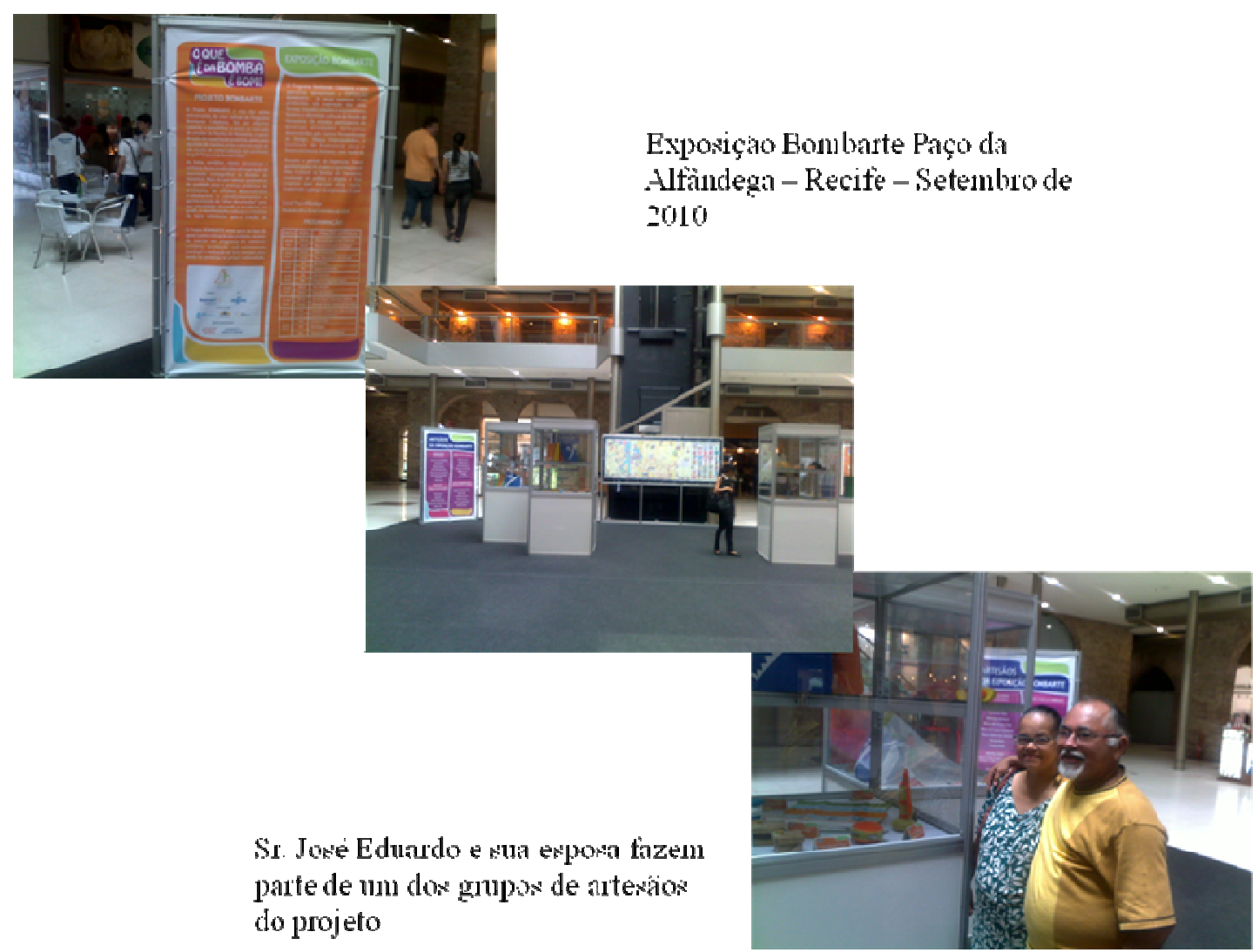

